\title{
ALFABETIZAÇÃO: UMA INDIVIDUALIZAÇÃO DO ENSINO?
}

\section{LITERACY: INDIVIDUALIZATION OF TEACHING?}

\author{
Tatiane Christine BIERKSTEKER*
}

Resumo: O presente trabalho tem como objetivos retomar os níveis propostos por Ferreiro (1986) na construção da linguagem escrita e propor estratégias que auxiliem os professores a solucionarem as dificuldades apresentadas pelos alunos durante o processo de alfabetização. Considera essencial que o professor observe a heterogeneidade presente em sala de aula. Propõe uma reflexão sobre o trabalho com a diversidade, destacando a necessidade da realização de um diagnóstico prévio (sondagem). Enfatiza a importância da interação entre professor e aluno enquanto fonte básica da criação de zonas de desenvolvimento proximal em sala de aula, bem como as interações com outros membros do contexto cultural em que a criança vive, as quais resultarão em novas conquistas intelectuais importantes para a aprendizagem.

Palavras-chave: Alfabetização. Dificuldade de aprendizagem. Heterogeneidade presente em sala de aula.

\begin{abstract}
The aim of the present article is to analyze the levels proposed by Ferreiro (1986) in the construction of written language and propose strategies that help teachers solve the difficulties students have in the process of becoming literate. It is essential that teachers take into consideration classroom heterogeneity. The article proposes a reflection about working with diversity emphasizing the need of a previous diagnosis. It also emphasizes the importance of interaction between teacher and student as a basic source of zone of proximal development in the classroom as well as the interactions with the other members of the cultural context in which the child lives which will result in important intellectual achievements for learning.
\end{abstract}

Keywords: literacy. Learning difficulties. Classroom heterogeneity.

\footnotetext{
* Mestre em Educação pela Universidade Federal do Paraná (UFPR). Professora da Faculdade Santa Amélia (SECAL) Ponta Grossa (PR). Coordenadora Pedagógica da Secretaria Mu-nicipal de Educação e Cultura de Carambeí (PR). christinetatiane@ hotmail.com
}

Olhar de professor, Ponta Grossa, 9(2): 377-390, 2006. 
Muitos são os textos e artigos dedicados à aprendizagem da linguagem escrita. No entanto, percebe-se que na prática pedagógica alguns tópicos devem ser retomados, visando ao avanço da práxis educativa.

No presente artigo, pretende-se compreender as etapas percorridas pelas crianças na construção da linguagem escrita, saber quais são as atividades mais adequadas aos diferentes grupos de alunos em sala de aula, rever a função do professor perante a construção do conhecimento do aluno, bem como retomar alguns aspectos relativos à teoria interacio-nista de aprendizagem.

Inicialmente, para explicar a ocorrência da aprendizagem, serão retomados conceitos relativos à teoria interacionista, que leva em consideração, além das condições externas, variáveis referentes à estrutura interna do sujeito. Na tentativa de utilização prática da teoria, muitas vezes, o professor possui uma visão simplificada e reducionista dos pressupostos que a fundamentam, tendo dificuldade em encaminhar uma prática pedagógica baseada na perspectiva interacionista, especialmente no que diz respeito ao ensino da linguagem escrita.

Para a criança construir conhecimento é necessário que ela saiba utilizar certos instrumentos culturais que a cercam, de natureza simbólica, os quais já existiam antes de os alunos iniciarem sua construção pessoal, sendo compartilhados pelos sujeitos do grupo social no qual a criança está inserida. Nessa perspectiva, Ferreiro (1986) salienta que a criança constrói conhecimentos desde que nasce e, na busca da compreensão do mundo que a cerca, levanta hipóteses e tenta solucionar cada caso à sua maneira. Portanto, assim que a criança entra em contato com o sistema de escrita, interage com ele e começa a interpretar o mundo letrado de forma que, ao ingressar na escola, já sabe muito sobre os signos escritos.

Porém, nem todos os significados da escrita são possíveis de serem interpretados pelos alunos. Às vezes, eles necessitam do auxílio de outras pessoas para compreenderem o sistema de representação desses signos construídos culturalmente, de uma intervenção daqueles que estão culturalmente mais preparados, alguém que seja capaz de entender o significado da vida em sociedade. Portanto, o papel dos professores torna-se fundamental, visto que são eles que planejam os conteúdos a serem trabalhados com os alunos e que irão auxiliálos durante o processo de elaboração desses conhecimentos.

De acordo com Oliveira (1997, p. 60), o papel explícito do professor é "provocar avanços que não ocorreriam espontaneamente", ou seja, é fundamental a interferência do professor na zona de desenvolvimento proximal dos alunos.

Dentre os conhecimentos culturais de que a criança precisa se apropriar encontra-se a linguagem escrita, que 
deve ser trabalhada de acordo com o momento natural do seu desenvolvimento. A cada estágio de desenvolvimento, a criança adquire meios de intervir de forma competente no contexto social em que está inserida, no qual a leitura e a escrita devem ser ensinadas naturalmente e de forma significativa para que seja possível o desenrolar de seu desenvolvimento ativo frente ao mundo em que vive.

\section{A AQUISIÇÃO DA LINGUA-} GEM ESCRITA PELA CRIANÇA

Em seus trabalhos, Emilia Ferreiro $(1985,1990,1995,2001)$ descobriu uma forma natural de a criança aprender a escrita, na qual passa por sucessivas etapas de compreensão a respeito dessa modalidade de linguagem. Verificou, também, que essa aquisição é um processo individual, próprio de cada criança.

Para o aprendiz, a construção da escrita é um processo que perpassa por desafios intelectuais, e nele ocorre construção de novos conceitos, cada vez mais elaborados. Assim, utilizando como suporte a teoria de desenvolvimento de Piaget, o qual verificou que a criança evolui na passagem de um esquema a outro nos estágios do desenvolvimento, construindo esquemas cada vez mais elaborados, Emília Ferreiro estudou a evolução da escrita infantil e observou que, para a criança compreender o sistema alfabético de escrita, ela passa por diferentes e sucessivos níveis de ela- boração do sistema de escrita.

Ferreiro, em seus últimos trabalhos, distingue três níveis, ordenados sob o ponto de vista do desenvolvimento, a saber: nível pré-silábico (que inclui o subnível intermediário I); nível silábico (que inclui o subnível silábico-alfabético ou intermediário II) e nível alfabético. Esses diferentes níveis do processo de construção do princípio alfabético foram estabelecidos por Ferreiro e Teberosky (1985), de acordo com as hipóteses formuladas pelas crianças a respeito do sistema de escrita.

Segundo Ferreiro (1985, 1990, 1995), no nível pré-silábico é comum a criança acreditar que objetos grandes (como "trem") são escritos com muitos caracteres e objetos pequenos (como "borboleta") são escritos com a utilização de poucos caracteres. Destaca-se que, nesse nível, a principal aquisição da criança é a distinção entre a escrita e o desenho, ou seja, ela passa a entender que, com os mesmos tipos de linhas, pode desenhar ou escrever. Nas palavras de Ferreiro (1995, p. 25):

Após uma série de explorações ativas, as crianças chegam à seguinte conclusão: não é o tipo de linha que nos permite distinguir entre um desenho e uma coisa escrita (...). A diferença está na organização das linhas. Quando desenhamos, as linhas são organizadas, seguindo-se os contornos do objeto; na escrita, as mesmas linhas não acompanham os contor- 
nos do objeto. Quando escrevemos, estamos fora do campo icônico. As formas da letra nada têm a ver com a forma do objeto ao qual as letras se referem, e sua organização nada têm a ver com a organização das partes do objeto.

Portanto, quando as crianças passam a distinguir a escrita do desenho, elas passam a compreender que as letras não reproduzem a forma dos objetos e, ao contrário do desenho, são organizadas de forma linear. Em síntese, esse primeiro nível de pensamento das crianças gera dois resultados: considerar sequiências de letras como objetos substitutos e distinguir a representação gráfica icônica (desenhar) da não-icônica (escrever). Após essa diferenciação entre desenhar e escrever, a criança precisa entender como essas duas formas de representação se relacionam, observando, gradativamente, que as letras são usadas para representar objetos do mundo e que o desenho é incapaz de produzir algumas palavras.

Segundo Seber (1997), como a escrita não possui semelhança com o objeto que representa, pelo fato de ser estabelecida por convenção, quando os primeiros rabiscos ou garatujas são nomeados pelas crianças, sua capacidade de representação simbólica começa a desenvolver-se, ocorrendo generalizações que farão evoluir seu pensamento abstrato.

$\mathrm{Na}$ opinião de Ferreiro, a função do professor, durante o nível pré-silábico, é diferenciar os traços dese- nhados e figurativos dos traços simbólicos da escrita para compreender o desenvolvimento da criança a respeito do sistema alfabético escrito.

A referida autora esclarece que a principal hipótese do subnível intermediário I diz respeito à necessidade de escrever de formas diferentes para ser possível a interpretação da escrita. Isto é, as crianças hipotetizam que, para existir significados diferentes, deve haver diferenciação na forma da escrita. Nessa etapa, além de empregarem uma quantidade mínima de letras para escrever (geralmente três), as crianças não escrevem com uma só letra ou sinal gráfico: variam as letras utilizadas e procuram escrever palavras diferentes de forma diversa.

Teberosky (1990) e Goodman (1995) concordam com Ferreiro (1986; 1995) no sentido de que uma escrita indiferenciada, com várias grafias iguais, representa a etapa inicial desse nível de elaboração escrita. Porém, no momento seguinte, a criança sente a necessidade de diferenciar tais grafias, variando seu repertório, sua quantidade ou sua posição. Assim, como em algumas crianças a disponibilidade das formas gráficas é limitada, há modificação na ordem linear da escrita, ou seja, são realizadas variações nas posições dos caracteres para que haja possibilidade de interpretação desses sinais. Caso a criança possua um repertório vasto de grafias, ela usará letras diferentes para a escrita de palavras variadas. 
Entretanto, se seu repertório for limitado, ela buscará alterar uma ou duas letras ou modificará sua posição para escrever palavras diferentes e solucionar seu problema cognitivo. Nesse nível, há um avanço considerável em relação ao nível precedente, porque a criança entende que as palavras desempenham um papel na escrita.

Ferreiro e Teberosky (1985) destacam, ainda, que a possibilidade de reproduzir um certo número de formas gráficas fixas e estáveis pode fazer aparecer duas reações diferentes nas crianças: um bloqueio, ou a utilização de modelos para prever outras escritas. O bloqueio acontece quando, após copiar um modelo fornecido por alguém, a criança não é capaz de reproduzi-lo sozinha posteriormente. Esse bloqueio pode distinguir-se em duas categorias: o bloqueio profundo (necessidade da presença constante do adulto, pelo fato de a criança sentirse insegura) ou momentâneo (quando o bloqueio fixa-se apenas por determinado tempo). Por outro lado, a criança pode utilizar modelos conhecidos para prever novas escritas, o que faz com que ela reflita constantemente acerca do que está construindo e avance na sua compreensão do sistema de escrita. No tocante à leitura, a criança exige, assim como o faz para a escrita, uma quantidade mínima de grafias (geralmente três) para ser capaz de interpretar algo escrito.

Em suma, a necessidade de diferenciar as palavras entre si faz com que a criança atente para as caracte- rísticas delas. Assim, ela inicia a descoberta de que partes das palavras (suas letras) podem ter correspondência com a quantidade de partes que se reconhece nas palavras faladas. Inicialmente, essa correspondência é silábica e isso define o próximo estágio de tal evolução.

No nível silábico, verifica-se uma correlação entre as partes da palavra escrita e sua expressão oral. É nessa fase que, pela primeira vez, a criança entende que a escrita representa partes sonoras da fala. Ferreiro e Teberosky (1985, p. 193) explicam que esse "nível está caracterizado pela tentativa de dar um valor sonoro a cada uma das letras que compõem uma escrita. Nessa tentativa, a criança passa por um período da maior importância evolutiva: cada letra vale por uma sílaba."

Entretanto, como afirma Seber (1997), na hipótese silábica podem aparecer grafias diferentes de letras, sendo que elas podem ou não ser usadas com um valor sonoro estável. Quando a criança usa grafias que não são consideradas como letras, pode se utilizar de formas circulares (fechadas ou semifechadas), acrescentando ou não uma linha vertical na escrita. No entanto, esses caracteres são expressos separadamente, sendo que cada caractere corresponde a uma sílaba da palavra falada. Ou seja, as crianças desenvolvem um critério de diferenciação, de forma que o número de sílabas da palavra falada é usado como referência para decidir com 
quantas letras essa mesma palavra deve ser escrita (tantas quantas forem as sílabas da palavra).

Na opinião de Ferreiro (1990), essa é uma etapa de fonetização da representação escrita. Nesse processo, a criança poderá escrever uma palavra utilizando-se apenas de vogais ou, caso observe a sonoridade das palavras, poderá escrever usando apenas consoantes. O professor deve estimular o raciocínio da criança para que ela descubra a sonoridade das letras confrontando a escrita de diferentes palavras semelhantes.

Segundo Ferreiro (1985), a construção da hipótese silábica pode ocorrer mediante uma estimulação externa, embora seja a própria criança que a constrói ao tentar passar da correspondência global entre a linguagem oral e a linguagem escrita para a correspondência de cada termo, o que a leva a atribuir um valor silábico para cada letra. Quando a criança trabalha com a hipótese silábica, as exigências de variação das letras e da quantidade mínima de caracteres desaparecem momentaneamente. Contudo, quando as letras começam a ser usadas com um valor silábico fixo, as partes sonoras semelhantes entre as palavras passam a ser expressas por letras semelhantes. Isso gera duas formas particulares de conflito: em primeiro lugar, como as palavras são escritas com um número maior de sílabas, algumas letras representam o som e outras não têm função. Nesse caso, o professor pode questionar a criança para verificar como ela resolve o conflito entre sua interpretação silábica e a realidade do escrito mais longo. Guimarães (2001) cita alguns exemplos de como isso ocorre: para ler a palavra "MARIA", a criança poderá repetir partes do nome [MA - MA RI - RI - A], ou pode ignorar o conflito, mantendo sua convicção silábica. Em segundo lugar, não há meios para diferenciar algumas palavras, uma vez que as mesmas letras representam diferentes sílabas. Por exemplo, se a criança utilizar apenas vogais, as palavras "MATO" e "PATO" poderão ser escritas com as letras "AO". No entanto, se ela utilizar apenas consoantes, poderá escrever as palavras "BOLA" e "BALA" da seguinte maneira: "BL". Outra forma de escrita que pode ser usada pela criança baseia-se na representação gráfica da consoante de uma sílaba e a vogal da outra sílaba; dessa forma, a criança poderá escrever tanto a palavra "BOLA" como a palavra "COLA" usando as letras "OL". Nesse caso, é importante que o professor questione a criança, para que ela possa perceber que existe algo que não está "correto" em sua escrita. Esse tipo de situação de conflito levará a criança a revisar sua hipótese e, eventualmente, descobrir que não basta grafar uma letra por sílaba.

Seber (1997) esclarece que o professor deve observar aquilo que a criança escreve, pois essa escrita reflete os avanços de sua organização interna. Nessa fase, não há necessidade de 
fazer correções, porque não há, do ponto de vista cognitivo, nada de errado na escrita infantil. O que existem são hipóteses por meio das quais a criança está construindo seu conhecimento. Todavia, o professor deve interferir no processo, questionando a escrita infantil, fazendo a criança refletir sobre o que faz com que ela consiga avançar no processo de aquisição do sistema de escrita.

O subnível silábico-alfabético pode também ser chamado de intermediário II, pois pode ser um estágio intermediário entre a hipótese silábica e a alfabética. Nesse momento, a criança começa a analisar a palavra em termos de sílabas e fonemas, produzindo uma escrita na qual algumas grafias representam as sílabas e, outras, os fonemas.

Seber (1997) ressalta que, em determinado momento, a criança usa poucas letras para escrever as palavras. Ao perceber isso, verifica a necessidade de maior quantidade de letras, voltando sua atenção aos aspectos fonêmicos. Nesse nível, Ferreiro $(1985$, p. 210) esclarece que a criança inclui mais letras na escrita das palavras, passando a perceber que suas palavras estão escritas de forma incompleta: "A hipótese silábica entra em contradição com o valor sonoro atribuído às letras". Por exemplo, a criança, ao escrever a palavra "MARIA", poderá apresentar a escrita das letras "MIA", ou seja, a letra "M" corresponde à sílaba "MA"; a letra "I", corresponde à sílaba "RI" e, pos- teriormente, à letra “A”. Ao perceber que sua escrita está incompleta, a criança passa a incluir mais letras para formar a palavra desejada, podendo apresentar a escrita "MAIA", com omissão da letra "R". Assim, existem palavras em que a criança insere sílabas inteiras; em outras, não. Ela percebe a necessidade de escrever sonoramente quando grafa uma palavra, em seguida, a lê e percebe que apenas aquelas letras não são suficientes para a realização de sua leitura, observando que as palavras precisam de quantidades específicas de letras. Diante disso, acrescenta algumas letras para compô-las "corretamente", de acordo com seu próprio ponto de vista (como exemplificado na escrita da palavra "MAIA").

Ferreiro (1985) explica ainda que, nesse momento, é difícil a criança coordenar todas as hipóteses que foi elaborando durante sua evolução; entre elas a da exigência de quantidade mínima de letras e a de que cada letra representa uma sílaba. É também difícil para ela trabalhar com o repertório de letras que o meio lhe fornece, bem como com as formas fixas estáveis que existem diante de si. Entretanto, é assim que a criança vai construindo o seu conhecimento a respeito da linguagem escrita. Destaca-se que, nesse nível, a criança ainda não escreverá "corretamente", pois não consegue realizar uma acurada análise fonológica das palavras de forma a identificar os fonemas.

Segundo Ferreiro (2001), quando 
o professor verifica que a criança está insatisfeita com sua escrita, deve fornecer ajuda para que ela possa refletir sobre suas hipóteses e avançar para a hipótese alfabética. A maioria dos professores espera que esse período transitório da passagem do nível intermediário II para o nível alfabético seja breve, contudo, tal passagem pode acontecer de maneira bastante lenta em algumas crianças. Por isso, o professor deve ser paciente, procurando auxiliar a criança para que ela reflita constantemente sobre o que está fazendo e consiga evoluir para o nível alfabético.

Grossi (1990) destaca que escrever usando o sistema de escrita alfabético compreende analisar as palavras em unidades mínimas de seus sons, ou seja, a criança consegue distinguir os diferentes fonemas, escrevendo cada letra de acordo com seu valor sonoro. Nesse nível não existem mais dificuldades em relação às leis de composição do código alfabético. Verifica-se isso claramente, na seguinte citação de Ferreiro (1985, p. 213):

A escrita alfabética constitui o final desta evolução. Ao chegar a este nível, a criança já franqueou a barreira do código; compreendeu que cada um dos caracteres da escrita corresponde a valores sonoros menores que a sílaba, e realiza sistematicamente uma análise sonora dos fonemas das palavras que vai escrever. Isso não quer dizer que todas as dificulda- des tenham sido superadas: a partir desse momento a criança se defrontará com as dificuldades próprias da ortografia, mas não terá problemas de escrita, no sentido estrito.

Portanto, a partir do estágio alfabético, as possíveis dificuldades de escrita centram-se nas grafias, que correspondem a vários valores sonoros. Assim, embora a criança já tenha compreendido as regras convencionais da escrita, observando a quantidade de segmentos orais e os relacionando com a mesma quantidade de letras, os erros surgem, pois as palavras passam a ser escritas de acordo com a escolha ortográfica que a criança realiza.

Seber (1997) considera que a compreensão da hipótese alfabética ocorre de forma natural. Se o professor não interromper esse processo de aquisição da criança com exercícios mecânicos e inadequados, ela perceberá a necessidade do uso de recortes orais e sonoros na composição de sua escrita. Ou seja, se a criança puder utilizar com liberdade o material gráfico, achará mais fácil combinar as letras com seus devidos significados.

Além disso, a referida autora enfatiza a importância da influência do ambiente social na construção do princípio alfabético de escrita. Na realidade, são as novas informações proporcionadas pelo meio social que possibilitam à criança sua constante modificação e reconstrução do conhecimento a respeito do sistema de es- 
crita. Assim, os conhecimentos sobre a escrita já construídos pelas crianças vão sendo modificados na medida em que ocorrem conflitos entre suas próprias interpretações da escrita e as provenientes dos sujeitos que dominam a linguagem escrita.

Como explica Ferreiro (1995), a cada tentativa de análise do sistema de escrita, a criança tenta assimilar as informações proporcionadas pelo meio ambiente, de acordo com seu próprio ponto de vista. Se ela conseguir apropriar-se dessas informações, aciona seus esquemas de assimilação e acomodação, modificando assim sua interpretação. Isso leva-a à aprendizagem de novos conceitos.

Acrescenta-se ainda que para a criança resolver os problemas que a escrita lhe apresenta, ela utiliza critérios próprios que lhe parecem mais adequados em cada momento, resultado de sua interação com o ambiente em que vive. Isso significa que existe sempre uma criança atuante e capaz querendo representar seu mundo social, interpretando constantemente o mundo em que está inserida.

Em suma, como observa Ferreiro (1987), para a criança chegar ao nível alfabético é necessário que a informação do meio ambiente seja pertur-badora. Entretanto, frente a uma perturbação, três tipos de reações da criança são possíveis: deixá-la de lado, compensá-la localmente ou assimilá-la. Quando a criança é capaz de assimilar as informações relativas ao princípio alfabético, ela abandona a hipótese silábica e reconstrói o sistema de representação sobre bases alfabéticas.

Contudo, apenas conhecer os níveis de construção de conhecimento da escrita pelos alunos não possibilita a melhoria da prática pedagógica do professor. Como afirma Ferreiro (1995, p. 33):

Levar a sério as conseqüências do desenvolvimento psicogenético significa colocar as crianças, com seus esquemas de assimilação, no centro do processo de aprendizado - percebendo-se que as crianças aprendem dentro de marcos sociais e não de isolamento. Significa aceitar que todos na sala de aula têm a capacidade de ler e escrever - cada um em seu próprio nível, inclusive o professor.

Logo, o professor deve colocarse no lugar da criança enquanto aprendiz. Isso quer dizer que, em alguns momentos, o professor fornecerá as informações de maneira direta e, em outros, de maneira indireta; em alguns casos, o professor deverá deixar a criança entrar em situações de conflito; em outros ele fornecerá soluções para a criança atingir seu conhecimento.

Assim, conhecer a psicogênese dos sistemas de interpretação elaborados pelas crianças para entenderem a representação alfabética da língua, significa pensar em ambientes de alfabetização que proporcionem a evolução da criança nesse processo, em lugar de apenas se ficar esperando que 
esse conhecimento se desenvolva. As crianças precisarão, muitas vezes, de auxílio, de assessoramento no desenrolar das atividades, e o professor deve estar atento para saber se deverá ou não interferir nesse processo, assim como para saber o momento em que deverá ocorrer a sua interferência e a maneira mais adequada de realiza-la. Ou seja, o educador deve aprender a trabalhar com a diversidade existente na sala de aula.

\section{TRABALHO COMA DIVER- SIDADE EM SALA DE AULA}

Nesta perspectiva, é essencial o educador entender as etapas percorridas pelos alunos na construção da linguagem escrita, de forma a propor atividades mais adequadas ao nível de aprendizagem em que seus alunos se encontram. Carvalho (2005, p. 52) ressalta que:

Nas salas de aula, não temos um sujeito epistêmico, temos, em média, 30 alunos que se encontram em várias fases de desenvolvimento, com a obrigação de ensinar a todos simultaneamente. Para tal, ao planejarmos uma atividade de ensino, é conveniente conhecer os procedimentos mediante os quais os alunos vão se apropriando progressivamente dos conteúdos escolares para que possamos intervir eficazmente em sua aquisição.

Porém, na efetivação da prática pedagógica dos educadores, o que acontece é que geralmente são propostas as mesmas atividades para todos os alunos. Há pouca preocupação do professor em oferecer atividades que correspondam ao nível individual de aprendizagem dos alunos (visto que seus alunos possuem níveis diferenciados de alfabetização, como foi exposto anteriormente). Assim, o professor utiliza um planejamento homogêneo para o trabalho com a turma, sem considerar a heteroge-neidade presente em sala de aula. Para que os alunos avancem em relação à aprendizagem, é necessário que o professor ofereça atividades adequadas ao nível de aprendizagem em que eles se encontram, o que leva à adoção de uma prática pedagógica que priorize a diversidade dentro da sala de aula. Isso implica atender às necessidades individuais que atingem a totalidade da turma (MAINARDES, 2005). Para sugerir atividades diferenciadas aos alunos é necessário, primeiramente, $\mathrm{o}$ professor fazer um diagnóstico de sua classe. Esse diagnóstico pode se dar por meio da aplicação da sondagem, a qual é um dos recursos que auxilia o professor a identificar os diferentes grupos, para propor atividades mais adequadas a cada aluno.

De acordo com Brasil (2000), a sondagem deve ser realizada individualmente com a criança, podendose utilizar uma relação de quatro palavras seguidas de uma frase. Após o professor ditar cada palavra individualmente, deve solicitar que o aluno a leia. É importante que haja registro 
da a escrita e da leitura do aluno em uma folha à parte. A relação das palavras ditadas deve iniciar com um polissílabo e terminar com um monossílabo. No entanto, é necessário tomar alguns cuidados na sua aplicação: não deve haver repetição de letras nas palavras (como em hipopótamo, por exemplo), não se pode ditar as palavras silabando e deve-se usar na frase pelo menos uma palavra utilizada anteriormente da lista (para verificar se o aluno possui uma escrita estável).

Numa segunda etapa, serão identificados os grupos existentes na sala de aula, conforme os níveis e subníveis de alfabetização propostos por Ferreiro (pré-silábico, intermediário I, silábico, intermediário II e alfabético).

Numa terceira etapa, o professor deverá planejar atividades diferenciadas de acordo com a necessidade dos diferentes grupos de sua turma. Algumas das atividades propostas podem ser realizadas coletivamente com a turma, como por exemplo: atividades de leitura, produção de texto coletivo, atividades de oralidade, entre outras.

Porém, outras atividades deverão ser realizadas de forma individualizada para atender às diferenças individuais dos alunos em sala de aula. Exemplificando: o professor pode iniciar a aula contando alguma história para os alunos e, em seguida, solicitar atividades de acordo com o nível de aprendizagem em que seus alunos se encontram. Assim, para alunos al- fabéticos, pode-se solicitar a produção de texto de forma individual; para alunos de nível silábico, pode-se propor uma atividade na qual eles completem uma cruzadinha de palavras previamente selecionadas da história lida; e para alunos pré-silábicos, podese auxiliá-los a formar algumas palavras utilizando o alfabeto móvel para, em seguida, efetivar a cópia dessas palavras no caderno.

Forneceremos um outro exemplo: o professor propõe uma cruzadinha para ser resolvida pelo grupo. Para os alunos alfabéticos, será entregue apenas a cruzadinha com suas figuras correspondentes; já para os alunos silábicos e pré-silábicos, pode-se apresentar as palavras escritas no final da folha, para que o aluno procure qual é a palavra que corresponde à solicitação realizada, o que fará com que ele reflita a respeito da sonoridade das letras.

Além disso, é de fundamental importância que o professor proporcione atividades nas quais os alunos interajam entre si de forma com que um auxilie o outro na construção do conhecimento, como defende Vygotsky, quando aborda a questão da mediação.

Assim, a atividade distinta considera que os alunos têm ritmos diferentes de aprendizagem, possuindo, portanto, necessidades distintas, o que requer do professor tomar atitudes diferenciadas para atender às diversidades existentes em sala de aula, fazendo com que todos os alunos avan- 
cem em relação ao seu próprio nível de aprendizagem. Para tanto, é necessário que o professor seja um mediador nesse processo de construção de conhecimento elaborado pelo aluno. Em outras palavras: em algumas situações o educador deverá explicar os conteúdos; em outras, demonstrar, auxiliar, corrigir, para que a criança avance em relação ao seu conhecimento. Essa é uma prática interacionista de alfabetização, na qual educador e educando interagem juntos na construção do conhecimento.

\section{CONSIDERAÇÕES FINAIS}

Valorizar o conhecimento que o aluno possui é uma das prioridades da concepção interacionista de aprendizagem. No entanto, para que essa valorização realmente ocorra é necessário, antes de mais nada, perceber a individualidade dos alunos em sala de aula.

Para que o aluno progrida no seu processo de aprendizagem, é preciso partir do nível de conhecimento que ele possui para levá-lo a um nível de conhecimento mais amplo. Isso ocorre diagnosticando-se individualmente o nível em que cada aluno se encontra, para propor atividades mais adequadas a cada grupo de alunos, a fim de que todos avancem no processo de construção da linguagem escrita.

O processo de alfabetização ocorre através da mediação entre a criança e a linguagem escrita, sendo fun- damental a mediação do professor, pois é ele quem pode auxiliar na zona de desenvolvimento proximal de seus alunos. O auxílio do professor - seja parando ou acelerando uma explicação; ajustando o planejamento inicial quando houver necessidade; ampliando ou não determinados aspectos trabalhados; propondo atividades adequadas ao nível de aprendizagem dos alunos; aproveitando um conteúdo bem compreendido como ponto de partida para aulas seguintes; fornecendo à criança pistas para solucionar algo que ela não consegue; ini-ciando uma atividade e deixando a criança finalizá-la, ou até mesmo possibilitando que as crianças se ajudem durante a execução da tarefa - favorece o processo de aprendizagem e, conseqüentemente, o desenvolvimento dos alunos. Essa forma de intervenção pressupõe que o professor deva, gradualmente, transferir a responsabilidade da execução das tarefas para as crianças. Além disso, é importante ressaltar que esse tipo de intervenção pedagógica implica muita sensibilidade do professor para com o que os alunos estão fazendo. Enfim, a interação entre professor e aluno é fonte básica de criação de zonas de desenvolvimento proximal em sala de aula, sendo que o ensino, como realização de tarefas de forma compartilhada ou apoiada, incrementa a capacidade de compreensão e atuação autônoma do aluno.

A interação da criança com pessoas mais capazes é importantíssima, 
porque são elas que fazem a mediação entre a cultura e o indivíduo, ou seja, possibilitam processos interpsicológicos que serão posteriormente internalizados pelo sujeito. Como afirma Vygotsky (1991, p. 64), "todas as funções superiores originam-se das relações reais entre os indivíduos humanos". Portanto, são as interações com os outros membros de sua cultura que resultarão em novas conquistas intelectuais, importantes para o desenvolvimento do pensamento da criança. Assim, ao interagir com seus alunos, o professor estará compartilhando os conhecimentos culturais que mais tarde serão internalizados por eles.

Essa é uma prática que prioriza o aluno enquanto construtor de seu conhecimento e o professor enquanto um mediador da aprendizagem.

\section{REFERÊNCIAS}

BRASIL. Ministério da Educação. Secretaria de Educação Fundamental. Programa de Desenvolvimento Profissional Continuado: parâmetros em ação - alfabetização. Brasília, 2000.

CARVALHO, A. M. P. Ensino de ciências e epistemologia genética. Viver Mente \& Cérebro, São Paulo, v. 6, p. 50-53, 2005. (Coleção Memória da Pedagogia)

FERREIRO, E. Desenvolvimento da alfabetização: psicogênese. In:

Reflexões sobre a alfabetização. 5. ed. São Paulo: Cortez, 1986.

Cultura, escrita e educação: conversas de Emilia Ferreiro com José
Antonio Castorina, Daniel Gondin e Rosa Maria Torres. Porto Alegre: ArtMed, 2001.

A escrita... antes das letras. In: SINCLAIR, H. A produção das notações na criança: linguagem, número, ritmos e melodias. São Paulo: Cortez, 1990.

FERREIRO, E.; TEBEROSKY, A. Psicogênese da língua escrita. Porto Alegre: Artes Médicas, 1985.

FERREIRO, E.; PALACIO, M. G. (Coords.). Os processos de leitura e escrita. Porto Alegre: Artes Médicas, 1987.

GOODMAN, Y. M. (Org.). Como as crianças constroem a leitura e a escrita: perspectivas piagetianas. Porto Alegre: Artes Médicas, 1995.

GROSSI, E. P. Didática da alfabetização: didática do nível pré-silábico. 3. ed. Rio de Janeiro: Paz e Terra, 1990.

GUIMARÃES, S. R. K. Dificuldades na aquisição e aperfeiçoamento da leitura e da escrita: o papel da consciência fonológica e da consciência sintática. Tese (Doutorado) - Universidade de São Paulo, São Paulo, 2001.

MAINARDES, J. Projeto Diferenciação: criando classes mais igualitárias por meio do trabalho diversificado. Carambeí, 15 jul. 2005. (Palestra)

OLIVEIRA, M. K. Pensar a educação: contribuições de Vygotsky. In: CASTORINA, J. A. et al. Piaget, Vygotsky: novas contribuições para o debate. 4. ed. São Paulo: Ática, 1997.

SEBER, M. G. A escrita infantil: o caminho da construção. São Paulo: Scipione, 1997.

TEBEROSKY, A. Psicopedagogia da linguagem escrita. São Paulo: Trajetória 


\section{Cultural, 1990.}

VYGOTSKY, L. S. A formação social da mente. 4. ed. São Paulo: Martins Fontes, 1991.

Encaminhado em: 15/06/06

Aceito em: 02/10/06 